\title{
VALIDATION OF EROSION MODELING: PHYSICAL AND NUMERICAL
}

Mehrad Kamalzare ${ }^{1}$, Christopher Stuetzle ${ }^{2}$, Zhongxian Chen ${ }^{2}$, Thomas F. Zimmie ${ }^{1}$, Barbara Cutler ${ }^{2}$ and W. Randolph Franklin ${ }^{3}$

${ }^{1}$ Rensselaer Polytechnic Institute, Civil and Environmental Engineering department, 110 8th Street Troy, NY 12180-3590

${ }^{2}$ Rensselaer Polytechnic Institute, Computer science department, 110 8th Street Troy, NY 12180-3590

${ }^{3}$ Rensselaer Polytechnic Institute, Electrical, Computer, and Systems Engineering department, 110 8th Street Troy, NY 12180-3590

\begin{abstract}
The overall intent of this research is to develop numerical models of erosion of levees, dams and embankments, validated by physical models. The physical models are performed at 1-g and at high g's using a geotechnical centrifuge. The erosion is modeled in detail, from beginning to end, that is from the time the levee is overtopped until the levee is breached. Typical quantities measured as a function of time are the depth, width and volume of rills, number of junction points, are the rills straight or meandering, sediment transport quantities, and finally breach. This data can be obtained from the numerical modeling, but is difficult to obtain from the physical modeling. Video images indicate the physical modeling agrees quite well with the numerical modeling. A comparison has also been done between observed breaching width and the FEMA new formula for both 1-g and centrifuge tests.
\end{abstract}

Keywords: Levee, Erosion, Digital simulation, Centrifuge tests, Overtopping.

\section{INTRODUCTION}


Levee failures that occur as a result of storm surges and flooding events are primarily due to overtopping, while another major failure mechanism is seepage. In both mechanisms, the erosive processes can eventually lead to breaching of the levee and catastrophic damage on the adjacent flood plain. A reliable prediction of the flood process, especially in a complex terrain is necessary for emergency plans for levee or dam breaches. Griffis, 2007 addressed the overall design of the engineering works that protect the City of New Orleans from major storm events. The history of the drainage of the city was briefly described, and the natural and engineered flood-protection structures and strategy for major hurricanes were discussed. This was followed by an analysis of the failures of the natural system, as well as failures of the levees, floodwalls, pumping stations, and the absence of flood gates on the canals. He eventually concluded that the "design storm" specified by congressionally authorized projects deserve reconsideration, and that engineering design reviews should be reorganized and implemented. Wan and Fell (2004) describe the development of two erosion rate tests, the Hole Erosion Test (HET) and Soil Erosion Test (SET), which measure soil erodibility. Using an Erosion Function Apparatus (EFA), Briaud et al (2008) investigated the erodibility of several different types of soil. The soils were classified into different categories of erodibility based on degree of compaction, erosion rate, water velocity and hydraulic shear stress. Xu and Zhang (2009) found that in addition to soil type, the degree of compaction plays an important role in erodibility of embankments. The erosion resistance increases with compaction effort, particularly with fine soils. Bryan and Rockwell (1998) studied agricultural sites near Toronto, Canada and found that significant rill incision typically occurred in early spring, immediately following snowmelt. However, this study relates levees or earth dams that are adjacent to water bodies and are saturated or can become saturated rapidly. Rills and gullies will form in areas of depression, or in areas where the soil does not have enough cohesion or shear strength to resist the hydraulic stresses from the flowing water. Factors affecting rill characteristics include the stress caused by the flow, roughness of the soil surface, slope gradient and soil erodibility (Mancilla, et al 2005). However, Govers, et al. 2007 stated that erodibility within a rill may vary with its depth, which can decrease the erosion process in granular soils, as a result of a reduced slope gradient. If a more erodible soil underlies the surface soil, however, the erosion rate in a rill or gully will actually be accelerated.

Post Hurricane Katrina field surveys showed that in general, rolled compacted clay filled levees performed well with minor erosion occurring when overtopped, whereas hydraulic filled levees with significant amounts of silt and sand performed poorly. Using good clayey material often required long haul distances that slowed construction progress. So nearby granular material was often used instead to construct the levees (Sills, et al. 2008). In cohesive embankments, breaching occurs as a result of head cutting, whereas in granular embankments, surface slips occur rapidly due to seepage on the downstream slope (Xu and Zhang 2009).

Experience resulting from Hurricane Katrina has shown that land side levee erosion due to wave overtopping can significantly limit levee performance and survival (USACE, 2008a). The options to ensuring levee integrity due to wave overtopping include: (1) a sufficiently high crest elevation such that overtopping does not occur, (2) armoring the levee land side such that the levee can withstand large 
amounts of overtopping, and (3) establishing a levee elevation that will allow an overtopping quantity that provides the levee the capability to withstand the induced erosion (Dean et al., 2009). Erosion is a time dependent process such that a levee can withstand various overtopping magnitudes for different durations. Although the specific interest may be in designing the levee for survival during a particular storm (e.g. a 100 year event), there is also interest in the erosional potential during storms that will cause greater overtopping. Flor et al. 2010, tested the relative importance of geologic, geomorphic, and other physical factors that have led to levee failures through the past century along the Mississippi River and presented some results that could potentially assist engineers and decision-makers in choosing appropriate locations and designs for levees. Dean et al. 2009, mentioned that present criteria for acceptable grass covered levee overtopping are based on average overtopping values and do not include the effect of overtopping duration. Therefore in their study, experimental steady-state results were applied for acceptable overtopping to the case of intermittent wave overtopping. Laboratory results consisting of velocities and durations for acceptable land side levee erosion due to steady flows were examined to determine the physical basis for the erosion. The governing equations for flow down the land side of a levee established that due to maximum velocity of water, the flows near the land side levee toe will be supercritical. Yu et al., 2009 carried out numerical simulations of levee or dam breach flow, often with constant flow parameters and in relatively simple channels rather than in natural rivers with complex boundaries using 2-D finite element models. The good performance of the model was demonstrated by comparisons of breaching with the theoretical solution of an idealized dam-break flow over a frictionless flat rectangular channel. The model was applied to simulate the flood propagation under complex boundary conditions. The unsteady flood process in a river and in the dry floodplain with a complex bed terrain was also simulated simultaneously. Xiao et al., 2008 applied a numerical wave model based on the incompressible Reynolds equations and $\mathrm{k}-\mathrm{e}$ equations to estimate the impact of overtopping on levees during storm surge. The free surface locations were represented by a volume of fluid function (VOF). The model was satisfactorily tested for an empirical equation of overflow discharge at a vertical seawall and experimental data of overtopping discharge at a sloping seawall. The validated model was used to simulate wave overtopping of the levee system during storm surge of Hurricane Katrina. The time history of wave profiles and velocity magnitude fields in the vicinity of the levees were demonstrated and analyzed.

As computer capabilities progress in representing hurricane induced storm surges, there is a need to improve understanding of the overtopping erosion potential and to provide associated guidance for more rational design (Dean et al., 2009). Although much work has been done to simulate erosion, very little of the results have been validated. A primary objective of this research was validation of the computer simulation by laboratory experimentation. Therefore in this paper, laboratory tests with different soils have been performed to improve the computer simulations of levee erosion. Previous tests have been performed using different mixtures of two soils and the effects of different percentages of clay have been investigated previously (Gross et al., 2010). The emphasis of this paper was to investigate the effect of water flow on the erosion. Therefore, all the tests were performed on one mixture of soil ( $25 \%$ clay, $75 \%$ sand) and water was added using various water flow rates. To better 
evaluate the effects of water flow on real levees, some centrifuge tests have also been performed which simulate full scale prototype levees and embankments.

\section{TEST MATERIAL}

A mixture of two soils have been used in the tests represented herein, a clay soil (Kaolinite Clay) and a granular soil (Nevada 120 Sand). Tests were performed on mixtures of $25 \%$ clay and $75 \%$ sand, which is almost prevalent in many levees around the world. Maximum dry density and optimum water content of the sand and clay were $16.4 \mathrm{kN} / \mathrm{m}^{3}$ and $11 \%$ for the sand and $12.8 \mathrm{kN} / \mathrm{m}^{3}$ and $29 \%$ for the clay respectively. Table 1 lists the physical characteristics of the mixed soil, while Fig. 1 shows grain size distribution curves of the pure sand and the mixed soil. The mixed soil is classified as SC according to the Unified Soil Classification System (USCS). The maximum dry unit weight for the soil sample was $15.4 \mathrm{kN} / \mathrm{m}^{3}$. Samples were prepared to achieve a relative density of $90 \%$ of the maximum dry density $\left(13.9 \mathrm{kN} / \mathrm{m}^{3}\right)$ and used the optimum water content $(10 \%)$ which has been calculated according to AASHTO T99-70 / ASTM D698-70 (A-method).

Table 1. Soil Characteristics

$\begin{array}{cc}\text { Property } & \text { Mixed soil } \\ \mathrm{D}_{10}(\mathrm{~mm}) & 0.074 \\ \mathrm{D}_{30}(\mathrm{~mm}) & 0.11 \\ \mathrm{D}_{60}(\mathrm{~mm}) & 0.19 \\ \text { Coefficient of uniformity } & 2.57 \\ \text { Coefficient of curvature } & 0.86 \\ \text { Liquid limit } & 17 \\ \text { Plastic limit } & 11 \\ \text { Permeability } & 10 \mathrm{e}-5 \mathrm{~cm} / \mathrm{s} \\ \text { USCS symbol } & \mathrm{SC}\end{array}$

Fig. 1. Grain size distribution curves of soils 


\section{TEST PROCEDURES}

The models used in this research were constructed in an aluminum box having a wall thickness of $0.0254 \mathrm{~m}$ and interior dimensions of $0.91 \mathrm{~m} \mathrm{~L} \mathrm{x} 0.61 \mathrm{~m} \mathrm{~W} \times 0.36 \mathrm{~m} \mathrm{H}$. The geometry of the model levee was determined similar to conventional real levees before construction of the model began. The dimensions were marked on the sides of the model box at the proper angles to ensure that the model levee was constructed to the desired specified geometry (Fig. 2(a)). Some other tests were also performed in smaller boxes to find the effect of dimensions of levee on the results (Fig. 2(b) and(c)). The compaction of soil was conducted manually by using a plastic hammer to hit the steel plate, which was placed on top of the soil until reaching the target unit weight.

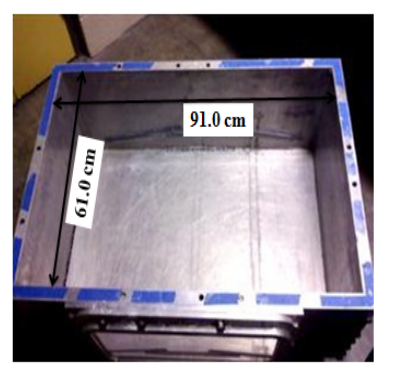

(a)

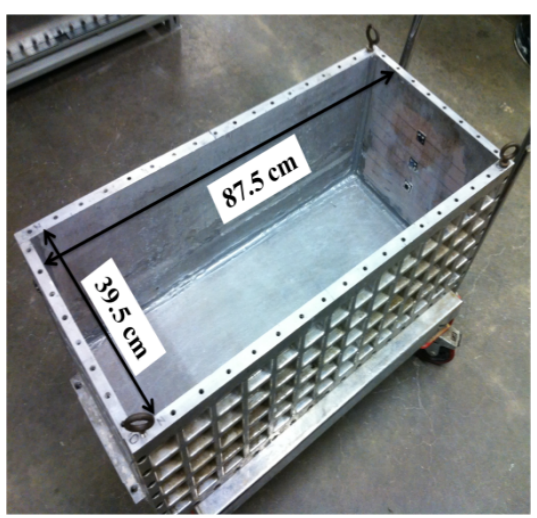

(b) 


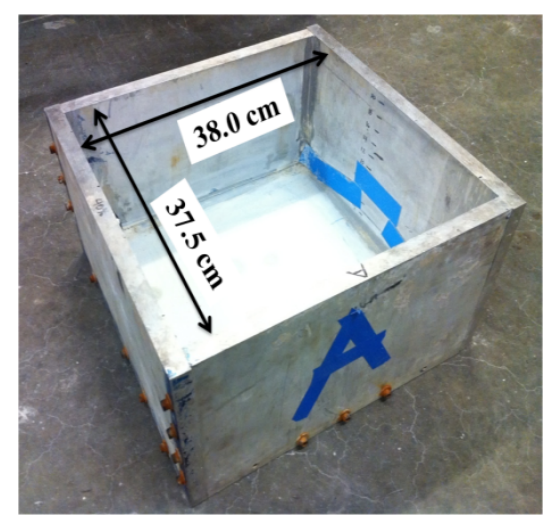

(c)

Fig. 2. Aluminum model boxes (a). Big box, (b) Medium box, (c). Small box

The erosion processes described in this paper refer to hydraulic erosion. Small-scale erosion on earthen embankments is being studied, modeled and eventually simulated, with respect to the formation of rills and gullies. Validation of the simulation is a primary focus in this research, so scaled-down model levees are used to perform erosion experiments at 1- $g$ and at higher levels of $g$ in a geotechnical centrifuge. The results of experiments to date are presented in the following sections. Different water flows were used and complex geometries and boundary conditions utilized to quantitatively assess the effects of differing conditions. The physical models serve as the basis for developing accurate, digital simulations of the embankment erosion processes. To illustrate the dimensions of the levee, a schematic picture of the model is shown in Fig. 3.

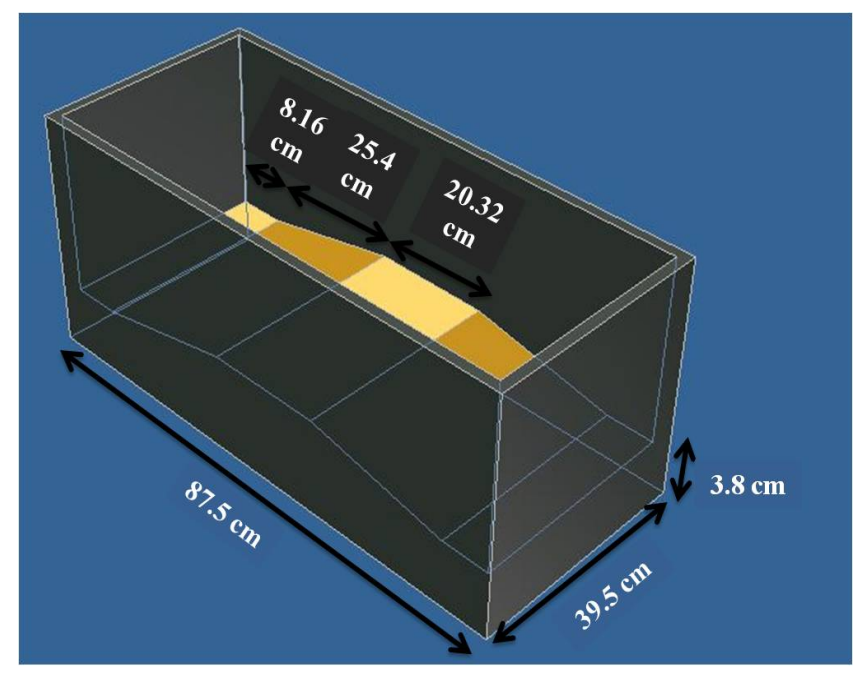

Fig. 3. Dimensions of the modeled levee in the medium box 
The time elapsed from initiation of initial rill erosion began at the crest of the landside slope to the time the eroded channel reached the crest on the waterside slope $\left(t_{\text {breach }}\right)$ was measured during the tests. Photographs and videos were taken before, during and after each test.

In order to do some large scale measurements centrifuge tests were performed at 20g's (Fig. 4(a)). Since in high $\mathrm{g}$ tests water will be heavier, erosion will occur much faster than 1-g. A high speed camera was used to take pictures and record videos during the tests in centrifuge. The camera is a V5 High Speed CMOS Camera with full image resolution 1024x1024 pixel array capability at 60,000 pps. Two other cameras were also recording videos from different angles. These videos and pictures were being used to evaluate the results of digital simulations and computer predictions.

Fig. 4(b) shows a levee after a centrifuge test. The erosion took around 5 minutes for a water flow equal to $0.56 \mathrm{lit} / \mathrm{min}$. However since in centrifuge time and dimensions will scale by $g$ this would be equal to 100 minutes in real life. The tested levee would also resemble a $17.50 \mathrm{~m}$ long levee with $1.78 \mathrm{~m}$ height and $7.90 \mathrm{~m}$ width.

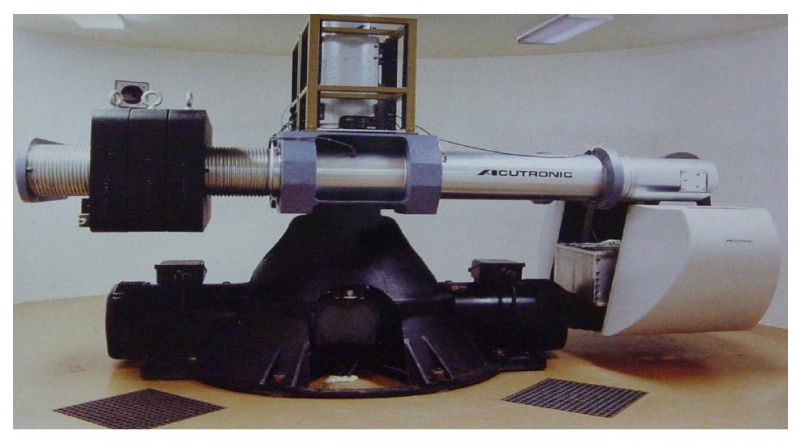

(a)

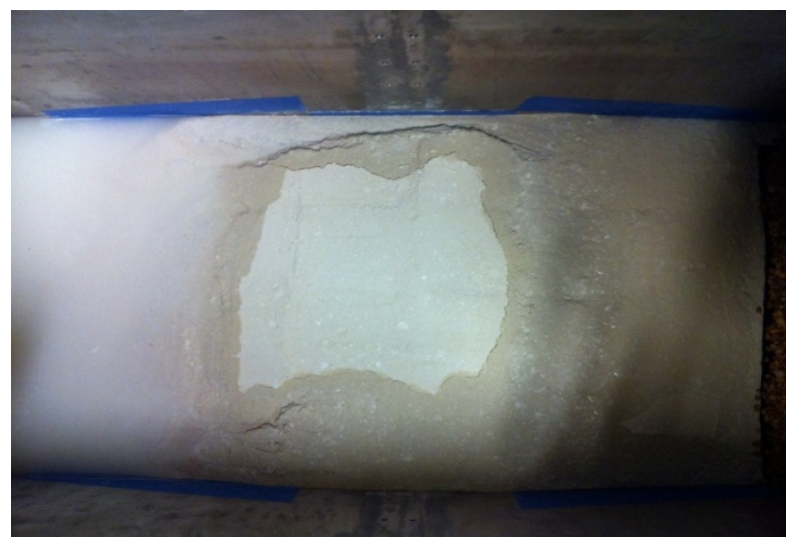


Fig. 4. (a). RPI 150 g-ton geotechnical centrifuge, (b). The eroded levee after the centrifuge test

Erosion simulation system is based on theories of Smoothed Particle Hydrodynamics (SPH) (Monaghan 1992). Both the water and the levee are discretized by particles, and the behaviour of fluid is modeled by the Navier-Stokes equations. In each of the simulations, approximately 450,000 and 2,500,000 particles are used to represent the water and the soil, respectively (Chen et al. 2011).

In simulations, the erosion rate, "z", (mm/hr) is modeled by using Eq. 1:

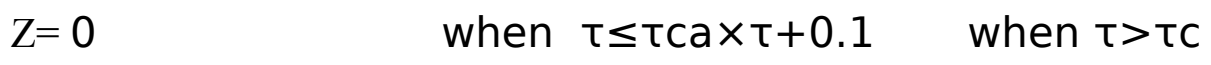

(1)

where $\tau$ is the hydraulic shear stress $(\mathrm{Pa})$ and $\tau_{c}$ is the critical shear stress. Since the values of $a$ and $\tau_{c}$ are different for different materials, their values have to be determined for each material used in physical experiments. In the authors' previous experiments, pure sand and sand-clay mixtures $(85 \%$ sand and 15\% clay) have been used. In previous simulations, the value for $a$ was estimated to be 187 and 93 for pure sand and sand-clay mixtures respectively, and the value for $\tau_{c}$ was estimated to be 2.0 and 3.0. A series of simulations on those two materials have been run, as well as some imaginary materials whose erodibility lies between the erodibility of those two materials (Chen et al. 2010). In order to determine the values of the parameters for the material of current experiments, a comparison between the results of previous simulations and the results of current physical experiments have been done.

Water flow rate, geometry of the levee surface, and erodibility of the soil were identified as three major components in the formation of channels during erosion simulation. A total of 27 computer simulations have been run, one for each possible combination of three different flow rates, levee downslope angles, and erodibility values. For flow rates, values of 8, 11, and $14 \mathrm{~mL} / \mathrm{s}$, relatively fast but not unrealistic rates were chosen. For erodibility values, 137, 159, and 187 alpha-values, representing the range from sand-clay mixture made up of approximately $10 \%$ clay to pure sand were chosen. Finally, for levee slope, dry-side slopes of 4:1, 5:1, and 6:1, ranges found in real levee design were chosen. For each simulation result, the time to breach was visually determined, as been identified by the Dam-Break Flood Forecasting Model.

\section{Results and discussions}


Times to breach statistics were observed to be based primarily on the flow rate of the water rushing over the levee. This appears logical, as a higher velocity implies more shear stress, and more opportunity to surpass the soil's critical shear stress and cause erosion. Secondarily, soil erodibility impacted the level of erosion as well. Within a single flow rate's time set, highly erodible soil failed first. The slope of the levee geometry had minimal impact on times to breach, an observation that is somewhat surprising considering how important levee slope is in the design of levees, as it has an impact on levee seepage and levee stability. However, at present our simulation does not model seepage or piping, nor does it consider large deformations of the levee due to mudslides or surface fracture. If these phenomena were modeled, the results may indicate levee slope as a more important factor during overtopping conditions.

Fig. 5 shows a visualization of the average times to breach of each experimental flow rate, levee slope, and soil erodibility.

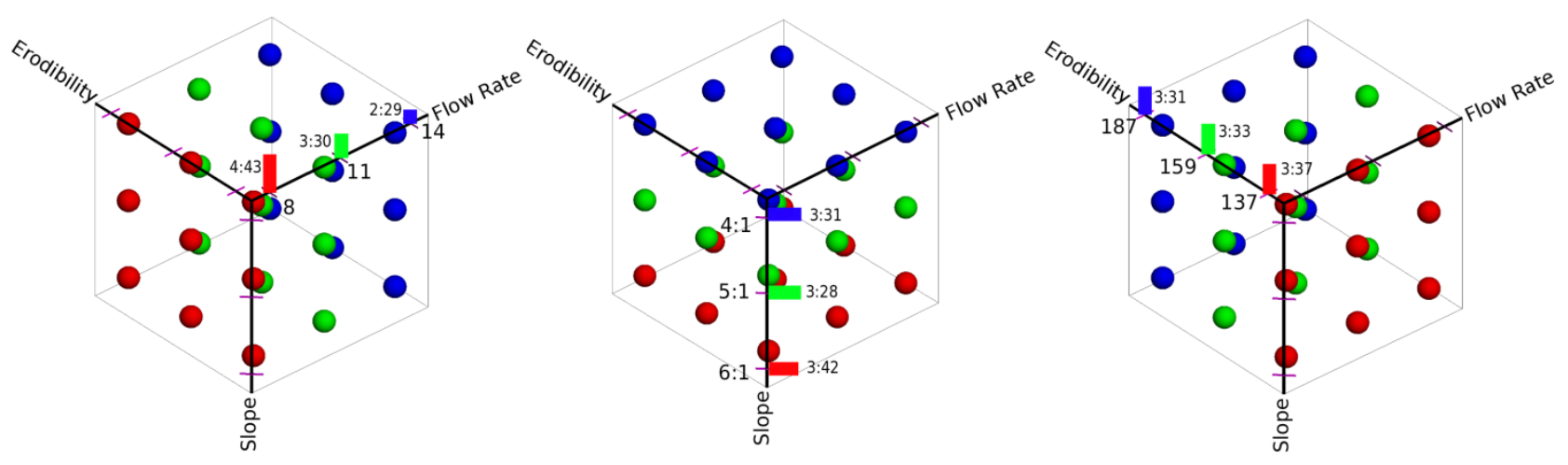

Fig. 5 A visualization of the average times to breach of each experimental flow rate, levee slope, and soil erodibility. Each data point represents a single erosion simulation, and planes are colored to represent the points that were used to determine a single characteristic's average time to breach. For instance, in the left image, all data sets with a flow rate of $8 \mathrm{~mL} / \mathrm{s}$ are represented by red, $11 \mathrm{~mL} / \mathrm{s}$ by green, and $14 \mathrm{~mL} / \mathrm{s}$ by blue data points. The bars on each axis represent the average time to breach of all data points of the corresponding color, and each image compares averages across a single characteristic. We can see that levee slope and erodibility have little effect on the times to breach, whereas flow rate has a major impact

An interesting outlier in our data was the fastest flow rate $(14 \mathrm{~mL} / \mathrm{s})$ and the highest erodibility value $(=187)$. All levee slopes in this category failed within 20 seconds of each other, and it was not the fastest time to breach, as would be expected. This result may indicate that there is a critical flow rate past which any flow is too destructive to adhere to any general trends. However, it is more likely that 
this anomaly is a result of the number of channels witnessed, an additional observation made of the test results.

The number of channels that formed under each testing condition was also observed. We designated the number of channels by two numbers, $n / m$, where $n$ is the number of channels visible on the downslope side of the levee, and $m$ is the number of channels that reached full breach during the test. The majority of tests presented a 1/1 channel result, meaning exactly one primary channel formed and it reached breach condition. The majority of tests in which a 2/2 channel formation was observed had flow rates of $14 \mathrm{~mL} / \mathrm{s}$, whereas the majority of the tests with flow rate of $8 \mathrm{~mL} / \mathrm{s}$ had a $1 / 1$ channel condition. The tests with flow rate of $11 \mathrm{~mL} / \mathrm{s}$ provided both $2 / 1$ and $1 / 1$ channel conditions, but no $2 / 2$.

The large number of tests with fast flow rates and multiple channel formations could account for the slower breach times for faster flow rates, as more soil is being eroded from two different locations along the levee, instead of a single channel. Since the total eroded volume is higher with faster flow rates, this appears logical.

A comparison has also been done between observed breach width in 1- $g$ and high- $g$ laboratory tests and FEMA ( Federal Emergency Management Agency) new levee breach equation (Eq. (2)).

For levees shorter than $7 \mathrm{ft}(2.13 \mathrm{~m})$ and longer than $2 \mathrm{ft}(0.61 \mathrm{~m})$ :

$$
\mathrm{B}=2.5 \mathrm{H}_{\mathrm{L}}+0.50 \mathrm{H}_{\mathrm{L}}^{2.77}
$$

where $B$ is final breach width and $\mathrm{H}_{\mathrm{L}}$ is average height from toe to crest of levee (ft). According to FEMA, this equation is valid for both sand and clay. Therefore it can also be used for a mixture of sand and clay like the soil that is being studied in this research. Since this is an empirical formula, FEMA mentioned that the range of acceptable breach width values is $+100 \%$ and $-50 \%$ of the breach width values computed by the above equation. Calculations show that the acceptable range is between $0.21 \mathrm{ft}$ $(6.4 \mathrm{~cm})$ and $0.84 \mathrm{ft}(25.6 \mathrm{~cm})$ for the levees that have been studied in this research. Table 2 shows different measured breach widths for $1-\mathrm{g}$ tests. However it should be mentioned that in $1-\mathrm{g}$ tests, the levee was only $2 \mathrm{ft}(0.61 \mathrm{~m})$ long. Therefore it is at the very lower boundary of valid range for FEMA formula.

\section{Table 2}

Different measured breach width

Water flow Breach width




$\begin{array}{cc}(\mathrm{Lit} / \mathrm{min}) & (\mathrm{ft}) \\ 0.88 & 0.15(4.57 \mathrm{~cm}) \\ 0.75 & 0.045(1.37 \mathrm{~cm}) \\ 0.65 & 0.083(2.53 \mathrm{~cm}) \\ 0.35 & 0.10(3.05 \mathrm{~cm}) \\ 0.20 & 0.14(4.27 \mathrm{~cm})\end{array}$

As it can be seen, the FEMA equation does not consider the water flow. However, the results of laboratory tests show that the breach width is different for different water flows. It can be also seen that none of the measured breach widths are in FEMA's acceptable range. As mentioned before, the levee would be $7.90 \mathrm{~m}$ long in centrifuge tests. FEMA suggests Eq. 3 for levees longer than $7 \mathrm{ft}(2.13 \mathrm{~m})$.

For levees longer than $7 \mathrm{ft}(2.13 \mathrm{~m})$ :

$$
\mathrm{B}=2.5 \mathrm{H}_{\mathrm{L}}+11.54 \mathrm{H}_{\mathrm{L}}^{1.16}
$$

The acceptable range would be between $52 \mathrm{ft}$ (15.85) and $208 \mathrm{ft}$ (63.40) for width of breach. However the results of laboratory test shows that the width of breach was only $14.4 \mathrm{ft}(4.39 \mathrm{~m})$. In all fairness, it should be noted that the FEMA equations (and many other similar empirical breach equations) are primarily intended for floodplain mapping.

\section{CONCLUSION AND FUTURE WORKS}

An investigation of various overtopping quantities dealing with levee erosion has been performed. Digital simulations have been presented to predict the time that it would take the levee to breach under different water flows. However still more centrifuge tests are needed to be run. Since the breaching in centrifuge tests are happening so fast, some modification may be needed for the centrifuge tests. E.g. using cameras with higher quality to become able to capture better images and videos during and after the tests. It can also help to observe and measure the exact breaching time during centrifuge tests; because even few seconds in high-g tests may be a lot more in real life. On the other hand, since the model is spinning in centrifuge, the breaching would always happen at the edges if the model be built 
flat (like 1-g tests). In future we are going to calculate how to build the models with some curve to avoid the breaching just happen at the edges of the box. The following specific conclusions can be drawn from the study:

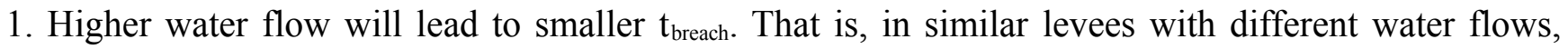
breaching would happen faster in the one which undergoes a higher water flow.

2. At higher water flows, most of the water will overtop the levee and the amount of water that seeps through the levee is negligible compared to overtopped water.

3. At smaller water flows (smaller that $0.4 \mathrm{lit} / \mathrm{min}$ ), the amount of water that seeps through the soil is significant compared to the amount of water that overtops.

4. At small water flows, seepage plays a significant roll on controlling the erosion. In the other words, although long time seepage may eventually cause failure but in short time it will prevent erosion.

\section{References}

Briaud, J.-L., Chen, H.-C., Govindasamy, A. V., and Storesund, R. (2008). "Levee Erosion by Overtopping in New Orleans during the Hurricane Katrina." Journal of Geotechnical and Geoenvironmental Engineering, 134(5), pp 618-632.

Bryan, R. B., and Rockwell, D. L. (1998). "Water Table Control on Rill Initiation and Implications for Erosional Response." Geomorphology, 23, pp 151-169.

Chen, Z., Stuetzle, C. S., Cutler, B., Gross, J. A., Franklin, W. R, and Zimmie, T.F. (2011). "Analyses, Simulations and Physical Modeling Validation of Levee and Embankment Erosion." Geo-Frontiers 2011, Texas, U.S.A.

Chen, Z., Stuetzle, C. S., Cutler, B., Gross, J. A., Franklin, W. R, and Zimmie, T.F. (2010). Quantitative analysis of simulated erosion for different soils. Proceeding GIS '10 Proceedings of the 18th SIGSPATIAL International Conference on Advances in Geographic Information Systems. ISBN: 978-1-4503-0428-3.

Dean, R.G., Rosati, J.D., Walton, T.L., and Edge, B.L. (2010). Erosional equivalences of levees: Steady and intermittent wave overtopping. Ocean Engineering, Vol. 37, (1), pp 104-113.

Flor, A., Pinter, N., and Remo, J. W.F. (2010). Evaluating levee failure susceptibility on the Mississippi River using logistic regression analysis. Engineering Geology Vol. 116, (1-2), pp 139-148.

Fred, D. L., Dambrk: The nws dam-break flood forcasting model. National Weather Service, Once of Hydrology, Silver Spring, Md, 1984. 
Govers, G., Gimenez, R., and Van Oost, K. (2007). "Rill Erosion: Exploring the Relationship Between Experiments, Modelling and Field Observations." Earth-Science Reviews, 84, pp 87-102.

Griffis, F.H. (Bud). (2007). "Engineering failures exposed by Hurricane Katrina." Technology in Society, Vol. 29, 2, pp 189-195.

Gross, J. A., Stuetzle, C. S., Chen, Z., Cutler, B., Franklin, W. R, and Zimmie, T.F. (2010). Simulation of levee erosion with physical modeling validation. Proceedings of the Fifth International Conference on Scour and Erosion (ICSE-5).

Mancilla, G. A., Chen, S., and McCool, D. K. (2005). "Rill Density Prediction and Flow Velocity Distributions on Agricultural Areas in the Pacific Northwest." Soil \& Tillage Research, 84, pp 54-66.

Monaghan, J. J. (1992). "Smoothed particle hydrodynamics." Annual Review of Astronomy and Astrophysics. 30: pp 543-574.

Sills, G. L., Vroman, N. D., Wahl, R. E., and Shwanz, N. T. (2008). "Overview of New Orleans Levee Failures: Lessons Learned and Their Impact on National Levee Design and Assessment." Journal of Geotechnical and Geoenvironmental Engineering, 134(5), pp 556-565.

U.S. Army Corps of Engineers (USACE). (2000). Design and Construction of Levees. Engineer Manual. Washington D.C.: Department of the Army.

Wan, C. F., and Fell, R. (2004). "Investigation of Rate of Rate of Erosion of Soils in Embankment Dams." Journal of Geotechnical and Geoenvironmental Engineering, 130(4), pp 373-380.

Xiao, H., Huang, W. and Tao, J. (2009). Numerical modeling of wave overtopping a levee during Hurricane Katrina. Computers \& Fluids Vol. 38, (5), pp 991-996.

Xu, Y., and Zhang, L. M. (2009). "Breaching Parameters for Earth and Rockfill Dams." Journal of Geotechnical and Geoenvironmental Engineering, 135(12), pp 1957-1970.

Yu, Ming-hui, Deng, Yin-ling, Qin, Lian-chao, Wang, Dang-wei and Chen, Ya-ling (2008). Numerical Simulation of Levee Breach Flows Under Complex Boundary Conditions. Journal of Hydrodynamics, (ser B) Vol. 21, (5), pp 633-639. 